\title{
Application of exponential functions in weighted residuals method in structural mechanics. Part 1: axisymmetrical shell problem
}

\author{
I. V. Orynyak ${ }^{1}$ •Yu. P. Bai ${ }^{1}$
}

Received: 9 August 2020/ Accepted: 23 November 2020

\begin{abstract}
Weighted residuals method gained a wide popularity during last years especially due to its application in finite element methods. Its goal is in approximate satisfaction of the governingfferential equations while boundary conditions are to be fulfilled exactly. This goal is achieved by the proper choice of the sets of so-called trial (basic) functions which give the residuals. Residuals are multiplied by weight functions and minimized by integration over the whole area of task. In fact, they determine the peculiarity and advantages of each particular method. Most popular is the choice of trial and weight (test) function as the trigonometric and polynomial functions. In 2D applications so-called "beam functions" are often used, which are solutions of much simpler 1D problems for beam. In this methodological paper we explore the possibility of using the sets of functions constructed on the consequent exponential functions, which satisfy boundary conditions. The method is investigated on example of very simple 1D axisymmetrical task for shell, where exact solution exists for any loading. For several examples of distributed or concentrated loading the proposed method is compared with similar Navier's method, which is the expansion on trigonometric functions. Also the proper choice of weight functions is carefully investigated. It is noted, that proposed sets (symmetrical or asymmetrical) of exponential functions has a good perspective in application for more complicated problems in structural mechanics.
\end{abstract}

Keywords: axisymmetrical shell, distributed loading, concentrated force, Navier method, Galerkin method, sets of exponential functions.

\section{Introduction}

Consider usual one dimensional differential equation with a right part:

$$
G(y)=f(x),
$$

where $G(y)$ - operator with respect to the looking for function $y, f(x)$ is a right part, which in structural mechanics is usually an outer loading. Essence of classical approach is in finding the sum of arbitrary particular solution and general solution of homogeneous equation, which consists of several eigenfunctions (their number is equal to the order of differential equation), and each is factored by unknown coefficient. They are to be found from boundary conditions.

\footnotetext{
I. V. Orynyak orynyak.iv@gmail.com

Yu.P.Bai ju.p.bai@gmail.com

${ }^{1}$ National Technical University of Ukraine "Igor Sikorsky Kyiv Polytechnic Institute”, Kyiv, Ukraine
}

Construction of a particular solution is usually an easier task, because it always possible to present the right part as a combination of functions which admit the convenient solution. If this particular solution additionally satisfies the boundary conditions, then it can be considered as an accurate one for the whole problem. In fact, this idea is the basis of weighted residuals method (WRM). Initially WRM was applied to approximate analytical treatment of the problem, when each function was applicable to the whole geometry. Later WRM along with variational methods became the common basis for finite element method [1], which is the most powerful tool for solution of various technical and scientific tasks.

Historically the first and still the most popular kind of WRM for treatment of differential equations of mathematical physics is Galerkin method, which in Russian literature is called as Bubnov-Galerkin method [2]. This is explained that few years before the famous work of Galerkin (1915 year), Bubnov in his review of Timoshenko's work on stability, where the variational energy principle was used, noticed its equivalence with expansion of looking for solution by orthogonal functions [2]. The essence 
of Galerkin's method consists in following [3]. Looking for approximate solution is presented as a sum of known functions $\phi$ with unknown coefficients $a_{n}$ :

$$
y=\phi_{0}+\sum_{k=1}^{N} a_{n} \cdot \phi_{k}(x), \quad 1 \leq k \leq N,
$$

where $\phi_{0}$ satisfies to known (nonzero) boundary conditions, while all other, so-called trial (basic) functions $\phi_{k}$, satisfy to zeros boundary conditions. Then notion of residuals $R$ of differential equation (1a) is introduced:

$$
R=G\left(\phi_{0}\right)+\sum_{k=1}^{N} a_{k} G\left(\phi_{n}\right)-f(x) \neq 0
$$

Evidently that goal is in minimization of the residuals. In Galerkin method this is provided integrally. With this aim the residuals is consequently multiplied on each basic function $\phi_{k}$, integrated over the whole area $S$ and equated to zero, thus:

$$
\int_{S} R(x) \cdot \phi_{m}(x) d x=0, \quad 1 \leq m \leq N .
$$

Evidently that the problem is reduced to the system of algebraic equations, the number of which in (1d) corresponds to the number of unknown coefficients in (1b).

Idea of Galerkin was very fruitful and gave rise to other variants of WRM. Their difference is that instead of application of basis functions $\phi_{m}(x)$ in (1d), quite different functions $\psi_{m}(x)$ can be used, and (1d) becomes:

$$
\int_{S} F(x) \cdot \psi_{m}(x) d x=0, \quad 1 \leq m \leq N
$$

where $\psi_{m}(x)$ are the weight (or test) functions. Thus in Galerkin method the trial and test functions are the same. Other variants of WRM are described in fundamental book of Fletcher [4]. Discern among them the least square method, LSM, which minimizes the integral from the square of $R(x)$. Designate:

$$
G\left(\phi_{k}\right)=\omega_{k}(x) .
$$

Then it can be shown [4], that LSM is also reduced to (1e), where $\psi_{m}(x)=\omega_{m}(x)$.

The choice of trial and test functions constituents the peculiarity and advantages of each particular WRM. As to general recommendations of Fletcher [4]:

- test functions should pertain to the same family of functions as the trial ones;

- as trial as test functions should be linear independent;

- trial functions and test functions should be first $N$ elements of the complete system of functions;

- basic functions should exactly satisfy to boundary (and initial, if applicable) conditions.
These are very general recommendations, so in most case investigators rely on available experience. The concrete appearance of test and trial functions is promoted by convenience and type of task. The orthogonal systems of functions are mostly used in textbooks. In some application there is no border between the different variants of WRM, because the trial function and operators from them are the same functions. This takes place when operator contains even differentials and trial function is chosen as sinus or cosines. Trigonometric functions and orthogonal polynomials (Legendre, Hermite, Chebyshev) in WRM are used very often. Yet while appearance of trial functions is suggested by the geometry and operator, the choice of zeros $\phi_{0}$ is a quite a problem, which influences the rate of convergence.

According to reference made in classic book of Timoshenko at el [5] the Navier method is the predecessor of WRM. In [5] the procedure of solution for simply supported rectangular plate is given, where the looking for function for displacement is expanded in Fourier series with respect to both coordinates. These functions are orthogonal, so system of equations (1d) is reduced to independent equations with respect to each coefficient $a_{k}$. Mention one additional advantage of Navier solution: even for case of concentrated outer loading when it actually becomes the boundary condition, it does not use the zero function $\phi_{0}$. This hints that usage of $\phi_{0}$ when some boundary conditions are non-zeros is not necessary, and only functions $\phi_{k}(x), k \geq 1$ can be used, while nonzero boundary condition can be considered as outer loading, thus be a part of $f(x)$ in (1a). Also point out two drawbacks of Navier method (usage of trigonometric functions). First, cosine and sinus functions usually converge rather slowly, especially in case of concentrated forces. Second, they can be used only for specific operators (has only even differentials) and boundary conditions, when zeros are the value of derivatives of the same evenness (for example, value of the function itself and its second derivative).

This work is methodological one, introductory to more serious problems, and is aimed on the explanation and extension of WRM capacities on example simple symmetrical and antisymmetrical task for simple one dimensional differential equation of $4^{\text {th }}$ order. It has three objectives:

First - to introduce exponential functions, especially for more complicated case of infinite body, when only decaying functions can be used, i.e. functions $\phi_{k}=\exp (-k x / L), x \geq 0$ and $L$ is constant. They have several advantages. A) Each derivative of them retains the same function. B) For localized forces and singularities these functions easily describe them by small number of terms. With respect to their behavior at $x \leq 0$, then it is easy to construct the supplemented function with employment of conditions of (anti)symmetry. 
Second - to investigate choice and significance of the test functions $\psi_{k}(x)$. The first recommendation of Fletcher about belonging of them to the same family as trial ones, is not completely clear. What is it, when trial functions are derived from specific family of functions. Here the cases will be considered when test functions are derivatives from the trial one up to $3^{\text {rd }}$ derivatives. Also variant of LSM will be used too.

Third - to investigate the possibility of omitting function $\phi_{0}$, when some conditions are non zeros, but can be accounted for as a part of outer loading. Here on example of concentrated force on the boundary it will be shown how the trial functions, which give zero force at the boundary, can be successfully used. This simplifies the application of WRM and allow to neglect function $\phi_{0}$, which is subjective and which do not usually belong to the same family as trial functions $\phi_{k}, k \geq 1$.

Investigations will be performed on example of known equation for deformation of axisymmetrical shell (or beam on elastic foundation). It is given in all handbooks on Strength of Materials, so analytical solution will be only outlined. For the sake of comparison the results by Navier method will be given too.

Of course, in structural mechanics WRM now is mostly used for 2D and 3D problems. Nevertheless, its application for beams (one dimensional structures) is still under consideration for more complicated material and loading behavior. Other value of such relatively simple considerations is that they lay basis for advanced analysis for plates or shells. As example we mention free vibration beam functions proposed in [7], which now are widely used for plate and shell analysis [8]; spectral element method [9]; or finite Fourier integral transforms technique, which initially was suggested to 4 th order beam problem [10] and subsequently was found to be very efficient for plate problem analysis [11].

\section{Governing equations, accurate solution and Navier approach}

Reducing the axial coordinate $x$ and the scale of loading, all the governing equation and differential relationships between different parameters of the task are given by:

$$
\begin{gathered}
\frac{d^{4} w}{d x^{4}}+4 w=p, \\
\frac{d w}{d x}=\gamma_{x}, \quad \frac{d \gamma_{x}}{d x}=M_{x}, \quad Q_{x}=\frac{\partial M_{x}}{\partial x},
\end{gathered}
$$

where $w$ is the radial displacement, $\gamma_{x}$-angle of rotation, $M_{x}$ - bending moment, $Q_{x}$ - transverse force and $p$ is the outer loading. Consider the following tasks.

Symmetrical tasks. Let the constant distributed loading be applied at the section $0 \leq x \leq l$, so:

$$
p=\frac{1}{l} \begin{cases}1, & 0 \leq x \leq l \\ 0, & \text { elsewhere }\end{cases}
$$

Factor $(1 / l)$ integrally equates force, which are applied at different lengths $l$, this allows to obtain comparable results. Two following conditions of symmetry:

$$
\gamma_{x}(x=0)=w^{\prime}(0)=0, \quad Q_{x}(x=0)=w^{\prime \prime \prime}(0)=0
$$

and conditions of decaying at infinity:

$$
\lim _{x \rightarrow \infty} w=0
$$

are used.

Asymmetrical task. Loading is similar to (3a), but the multiplier $1 / l^{2}$ is used

$$
p=1 \cdot\left(1 / l^{2}\right), \quad 0 \leq x \leq l
$$

to provide the equality of the applied integrated bending moment. The restriction on infinity (3c) is used too. And the conditions of asymmetry are:

$$
w(0)=0, \quad M(x=0)=w^{\prime \prime}(0)=0 .
$$

Concentrated force in symmetrical task. In spite that it is special case of (3a), we will single it out separately. Take instead of (3a) that:

$$
p(x) \equiv 0
$$

and instead of ( $3 b)$ the following conditions:

$$
w^{\prime}(0)=0, \quad Q_{x}(x=0)=w^{\prime \prime \prime}(0)=1 .
$$

Classical exact solution can be obtained in the following way. The geometry is broken out on two sections: $0 \leq x \leq l$ and $l \leq x \leq \infty$. On first section the general homogenous solutions is written (4 unknown constants) and particular solution (constant $1 /(4 l)$ ). On second section only general solution exists which due to restriction on infinity (3c) contains only two eigenfunctions with 2 constants. Six unknown constants are found from 2 conditions of symmetry ( $3 \mathrm{~b}$ ) and 4 conditions of conjugation between all 4 parameters $\left(w, \gamma_{x}, M_{x}\right.$ and $\left.Q_{x}\right)$ at the border between $1^{\text {st }}$ and $2^{\text {nd }}$ sections.

Separately write the well known solution for concentrated force:

$$
\begin{gathered}
w(x)=0.25 \cdot \exp (-x)(\cos x+\sin x), \\
\gamma_{x}=0.5 \exp (-x) \sin x \\
M_{x}=0.5 \cdot \exp (-x)(\sin x-\cos x) \\
Q_{x}=\exp (-x) \cos x
\end{gathered}
$$

Classical Navier method. As far as we know this task is treated by Navier method in first time, where in fact it assumes application of the cosine and sinus functions for 
approximate solution of (1a). For symmetrical task the loading is expanded by $\cos \frac{n \pi x}{L_{1}}$, where $L_{1}$, is some length; thus presents loading in the form:

$$
p(x)=\sum_{n=0} p_{n} \cos \frac{n \pi x}{L_{1}},
$$

where $p_{n}$ are expansion coefficients, for which we get:

$$
\begin{gathered}
p_{0}=\frac{1}{L_{1}} \int_{0}^{L_{1}} p(x) d x=\frac{l}{L_{1}}, \quad n=0 ; \\
p_{n}=\frac{2}{L_{1}} \int_{0}^{L_{1}} p(x) \cos \frac{n \pi x}{L_{1}} d x=\frac{2}{n \pi} \sin \frac{n \pi l}{L_{1}}, \quad n \geq 1 .
\end{gathered}
$$

Then equation ( $2 \mathrm{a})$ becomes:

$$
\frac{d^{4} w}{d x^{4}}+4 w=\sum_{n=0} p_{n} \cos \frac{n \pi x}{L}
$$

Its particular solution for the displacements $w$ gives the following series:

$$
w=p_{0} \frac{l}{4 L_{1}}+\sum_{n=1} \frac{p_{n} L_{1}^{4}}{(n \pi)^{4}+4 L_{1}^{4}} \cos \frac{n \pi x}{L_{1}},
$$

which automatically satisfies (3b).

Analogously for asymmetric loading we apply the expansion by sinuses, which satisfy to (3e). In similar manner we get:

$$
w_{-}=\sum_{n=1} \frac{p_{-n} L_{1}^{4}}{(n \pi)^{4}+4 L_{1}^{4}} \sin \frac{n \pi x}{L_{1}} .
$$

With respect to condition of decaying at infinity, it is necessary to take that conditional length of expansion $L_{1}$ should be bigger than sum of length of loaded section and theoretical wave-length of eigenfunction (see, for example, solution (4)). So, it is desirable that:

$$
L \geq l+(4 \div 6) \cdot 1 \text {. }
$$

In general case the influence of the chosen length of expansion $L_{1}$ should be carefully studied. Thus in Navier method the conditions at infinity are not used.

Application of decaying exponential functions. For convenience let's introduce the following designations for decaying exponential functions:

$$
\Gamma_{k}(x)=\exp (-k x / L), \quad 0 \leq x \leq \infty,
$$

where length $L$ is arbitrary and its influence on accuracy will be analyzed below. The sets of symmetrical functions $\Phi_{k}(x)$ which satisfy both (3b) and (3c) are introduced:

$$
\begin{gathered}
\Phi_{k}(x)=\alpha_{k, 0} \Gamma_{k}+\alpha_{k, 1} \Gamma_{k+1}+\alpha_{k, 2} \Gamma_{k+2}, \quad 0 \leq x \leq \infty, \\
\Phi_{k}(-x)=\Phi_{k}(x), \quad-\infty \leq x \leq 0 .
\end{gathered}
$$

Conditions (3c) are satisfied automatically due to properties of (6a). To satisfy (3b) we chose $\alpha_{k, 0}$ as equal to one, and other coefficients express by it, then:

$$
\begin{gathered}
\alpha_{k, 0}=1, \quad \alpha_{k, 1}=-\frac{2 k(2 k+2)}{(k+1)(2 k+3)}, \\
\alpha_{k, 2}=\frac{k(2 k+1)}{(2 k+3)(k+2)} .
\end{gathered}
$$

Analogously for asymmetrical loading introduce the following sets:

$$
\begin{gathered}
\Phi_{k}(x)=\beta_{k, 0} \Gamma_{k}+\beta_{k, 1} \Gamma_{k+1}+\beta_{k, 2} \Gamma_{k+2}, 0 \leq x \leq \infty, \\
\Phi_{k}(-x)=-\Phi_{k}(x),-\infty \leq x \leq 0,
\end{gathered}
$$

where coefficients are chosen to satisfy the asymmetry conditions (3e):

$$
\beta_{k, 0}=1, \quad \beta_{k, 1}=-\frac{2(2 k+2)}{(2 k+3)}, \quad \beta_{k, 2}=\frac{(2 k+1)}{(2 k+3)}
$$

Below consider in details the procedure of solution only to symmetric case. Insert (6b) in left side of differential equation $(2 \mathrm{a})$ :

$$
\frac{d^{4} \Phi_{k}}{d x^{4}}+4 \Phi_{k}=\Omega_{k}(x),
$$

where $\Omega_{k}(x)$ is function which is defined from (7a). Thus expression for $\Omega_{k}(x)$ can be presented as

$$
\Omega_{k}=\xi_{k, 0} \Gamma_{k}+\xi_{k, 1} \Gamma_{k+1}+\xi_{k, 2} \Gamma_{k+2},
$$

where

$$
\xi_{k, i}=a_{k, i} \frac{(k+i)^{4}+4 L^{4}}{L^{4}}, \quad 0 \leq i \leq 2 .
$$

Then let's describe the general procedure of WRM application. As was noted above the second almost equally important step is the choice of test functions $\psi_{k}$. Here the general hint of Fletcher about the belonging to same family of functions for both trial and test functions will be discussed. But what is the same class if all our functions are constructed from functions $\Gamma_{k}(x)$ ? Evidently we can construct from them the large number of combinations. As for considered task we already have 5 sets of function, which were created from $\Gamma_{k}(x)$. Thus as test functions we chose the following sets: $\Phi_{k}(x)$ for Galerkin method; $\Phi_{k}^{\prime}(x)$ are sets defining angle of rotation; $\Phi_{k}^{\prime \prime}(x)$ are expressions for moments; $\Phi_{k}^{\prime \prime \prime}(x)$ are transverse force functions; $\Omega_{k}(x)$ are the functions for outer loading. 
Proceed to WRM application. Present the displacement function $w$ as expansion in functions $\Phi_{k}(x)$ :

$$
w=\sum_{k=1}^{N} \gamma_{k} \Phi_{k} .
$$

Then from (1c) and (1d) ( $\left.\phi_{0}=0\right)$ we get the following system of equation:

$$
\sum_{n=1}^{N} \gamma_{k} \Omega_{k}(x) \cdot \psi_{m} d x=\int_{-\infty}^{\infty} p(x) \cdot \psi_{m} d x, \quad 1 \leq m \leq N .
$$

It can be presented in form:

$$
\gamma_{k} \cdot \omega_{k, m}=b_{m}
$$

where the matrix coefficients $\omega_{k, m}$ and free column $b_{m}$ are calculated with accounting of symmetry:

$$
\omega_{k, m}=2 \int_{0}^{\infty} \Omega_{k}(x) \psi_{m}(x) d x, b_{m}=2 \int_{0}^{\infty} p(x) \psi_{m}(x) d x .
$$

The system (8c) with coefficient (8d) is applicable to all variants of WRM. Consider procedure of calculation for loading (3a) on example of first case of choice of test functions, namely $\psi_{m}=\Phi_{m}$ (Galerkin method). So, for terms of free column we get:

$$
\begin{gathered}
\frac{b_{m}}{2}=\frac{\alpha_{m, 0} \cdot L}{m l}\left(1-\Gamma_{m}(l)\right)+ \\
+\frac{\alpha_{m, 1} \cdot L}{(m+1) l}\left(1-\Gamma_{m+1}(l)\right)+\frac{\alpha_{m, 2} \cdot L}{(m+2) l}\left(1-\Gamma_{m+2}(l)\right)
\end{gathered}
$$

Similarly, the expressions for matrix coefficients $\omega_{k, m}$ of system ( $8 b)$ also can be written analytically too:

$$
\frac{\omega_{k, m}}{2}=\int_{0}^{\infty}\left(\alpha_{k, 0} \Gamma_{k}+\alpha_{k, 1} \Gamma_{k+1}+\alpha_{k, 2} \Gamma_{k+2}\right) \times
$$

$$
\begin{gathered}
\times\left(\xi_{m, 0} \Gamma_{m}+\xi_{m, 1} \Gamma_{m+1}+\xi_{m, 2} \Gamma_{m+2}\right) d x= \\
=\sum_{i=0}^{2} \sum_{j=0}^{2} \alpha_{k, i} \xi_{m, j} \frac{L}{k+i+m+j} .
\end{gathered}
$$

Consider particular examples calculation for different loadings and variants of WRM.

\section{Example of calculation}

Let's demonstrate the efficiency and peculiarities of application of exponential functions for different loading with gradual transition to the most complicated case of concentrated force.

1. Initially consider loading (3a), where $l=0.5$. On Fig. 1 the calculated values of: a) displacement; b) moments, c) distributed outer loading are shown. As it seen from Fig. 1, $a$ that application of only 4 first terms in expansion (8a) (at $N=4, L=2$ ) gives visual accuracy of results. This relates to choice of test functions in form: as $\psi_{m}=\Phi_{m}$, as $\psi_{m}=\Phi_{m}^{\prime \prime}$ and as $\psi_{m}=\Omega_{m}$. Similar accuracy is achieved in Navier method for number of terms $N_{1}=10$ and value of length $L_{1}=7$.

The choice of test functions in form $\psi_{m}=\Phi_{m}^{\prime}$ or $\psi_{m}=\Phi_{m}^{\prime \prime \prime}$ (which also belong to the "family" of functions (6a)) will lead to no results, because the residuals $\Omega_{m}$ are symmetrical, while they are asymmetrical. Integrals of their product give zero. Thus we do otherwise. We take that angle of rotation is a symmetric function too, and respectively define its values for the range of negative $x$. Nevertheless the results of determination of displacement $w$ according to above procedure were quite unsatisfactory, and they are also shown on Fig. 1. This testifies that not each system of functions, which constructed from the same initial family of functions, can be used as the test one.

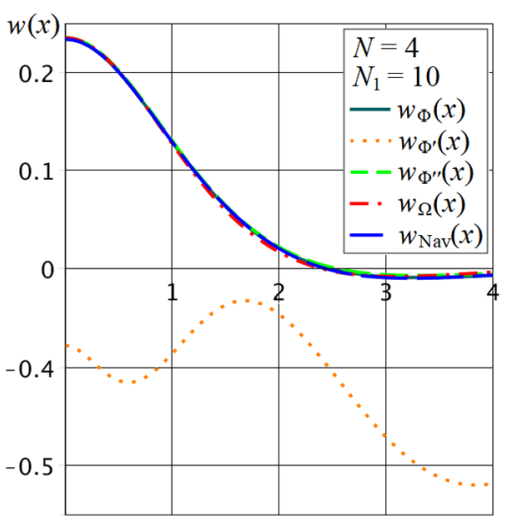

$a$

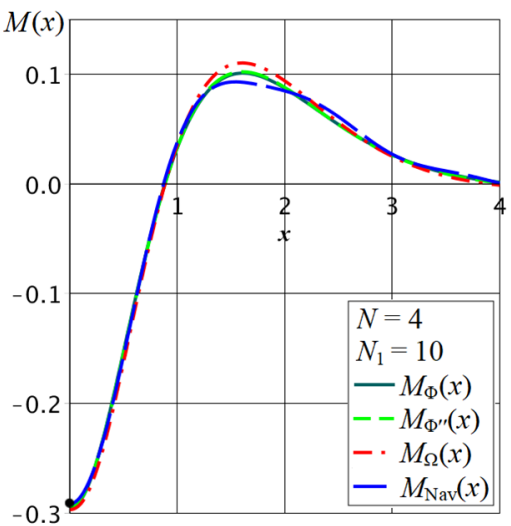

$b$

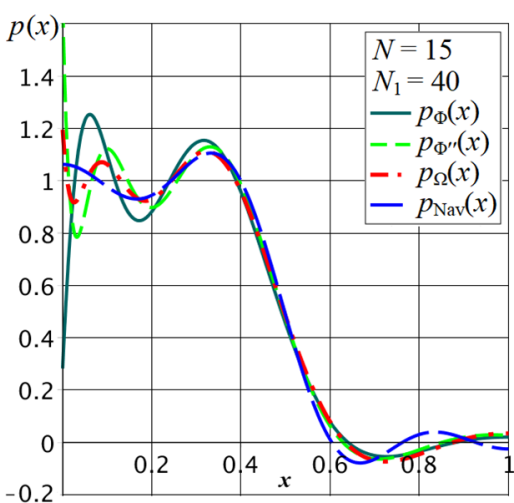

$c$

Fig. 1. Calculated values of $(a)$ displacement; $(b)$ moments; $(c)$ outer loading for symmetrical task at length of loading $l=0.5$ 
With respect to the graphs for moment (Fig. 1, b), then at $N=4$ they differ very little between themselves, while the best accuracy is attained (at least for point of maximum at $x=0$ ) at $\psi_{m}=\Phi_{m}^{\prime \prime}$. Of course increase in number of terms leads to very noticeable increase in accuracy and to coinciding of results. The worst results are for distributed loading. Navier method gives visual discrepancies even at number of terms equal $N_{1}=40$, while exponential functions require only 15 terms to give the similar appearance. In this case, the best accuracy is achieved for test function taken in form of residuals, i. e. $\psi_{m}=\Omega_{m}$.

2. Asymmetrical case. Let's again assume the length $l=0.5$ and investigate the application of 5 sets of function generated from the same "family" of (6a) as candidates for the test functions. As before, artificially modify the functions $\Phi_{m}^{\prime}$ and $\Phi_{m}^{\prime \prime \prime}$ by changing their type of symmetry in the interval $-\infty \leq x<0$. Note, that again results for $\psi_{m}=\Phi_{m}^{\prime}$ or $\psi_{m}=\Phi_{m}^{\prime \prime \prime}$ were quite unsatisfactory. So we do not show them on figures, nor will use them later. So, the choice of test function can also be a crucial step in WRM application.

Fig. 2 shows four calculated graphs for the displacements $w$ obtained due to following test functions:
$\psi_{m}=\Phi_{m}, \psi_{m}=\Phi_{m}^{\prime \prime}$ and $\psi_{m}=\Omega_{m}$ as well as obtained by Navier method. In this case application of even 6 terms of expansion still gives some visual discrepancies. Here Galerkin method gives the better results, while the worst ones are got for functions $\Omega_{m}$ (i.e. for LSM). Navier method again requires more terms. With respect to graphs of moment - the better results are achieved when $\psi_{m}=\Phi_{m}^{\prime \prime}$ (Fig. 2,b). As to reproduction of outer loading, the best results are got at $\psi_{m}=\Omega_{m}$ (Fig. 2,c).

3. Back to symmetrical case. Let's decrease the length of action of outer loading, so take $l=0.1$ (Fig. 3). Here it is evident that: first, for better results it is necessary to apply more terms $N$ in all expansions; and second, adoption of different test functions may lead to big difference. As above, note that adoption $\psi_{m}=\Phi_{m}$ gives very good values of displacement, slight worse results for moment, and worst results for loading. Adoption of function $\Phi_{m}^{\prime \prime}$ (moments) gives the best results for moments and generally good results for displacements; while adoption of $\Omega_{m}$ (distributed loading) as the test function $\psi_{m}$ gives best results only for outer loading reproduction. Note, that bold dot on Fig. 4, $b$ shows the exact value of bending moment

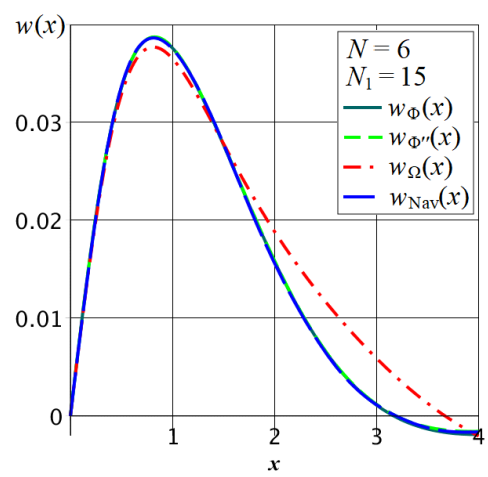

$a$

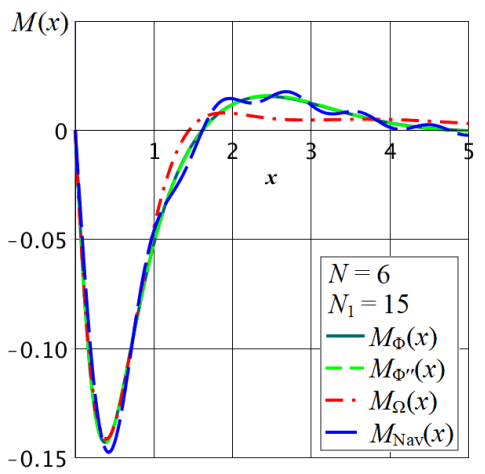

$b$

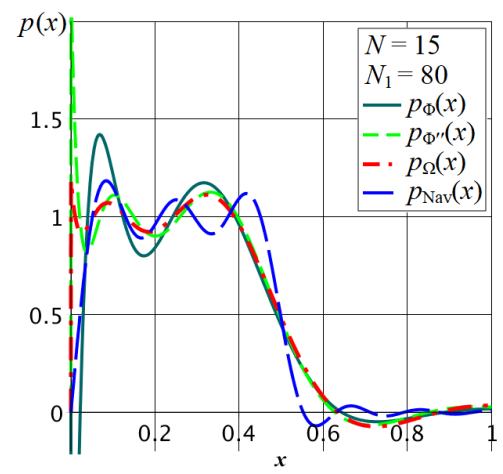

c

Fig. 2. Calculated values of $(a)$ displacement; $(b)$ moments; $(c)$ outer loading for asymmetrical task at length of loading $l=0.5$

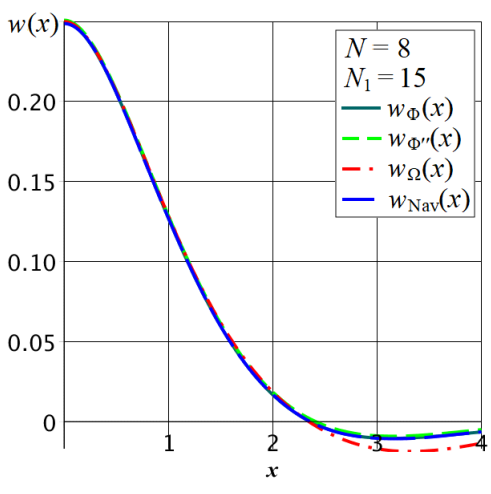

$a$

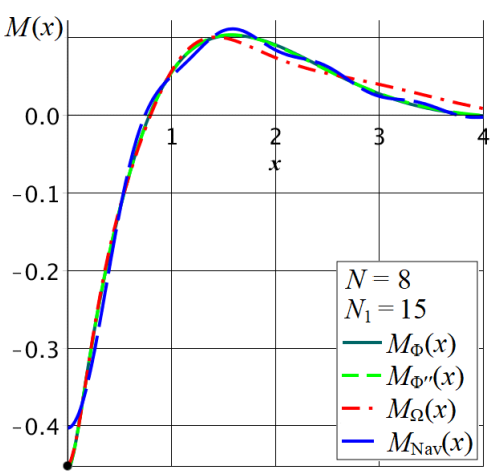

$b$

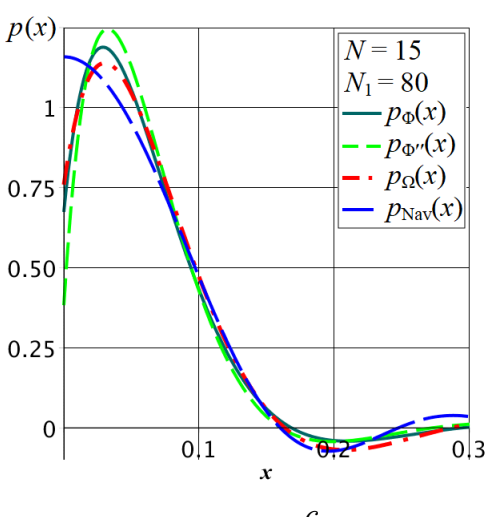

c

Fig. 3. Calculated values of: $(a)$ displacement; $(b)$ moments; $(c)$ outer loading for symmetrical task at length of loading $l=0.1$ 


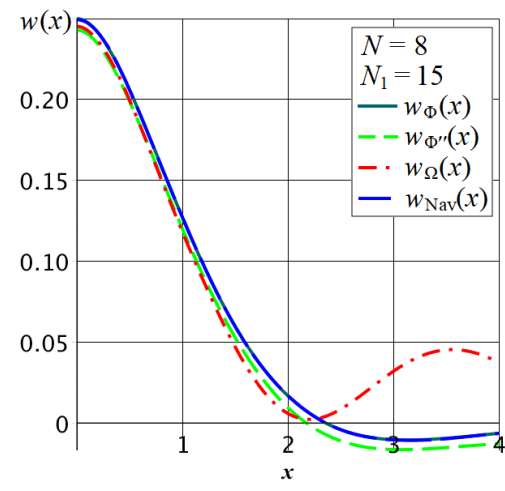

$a$

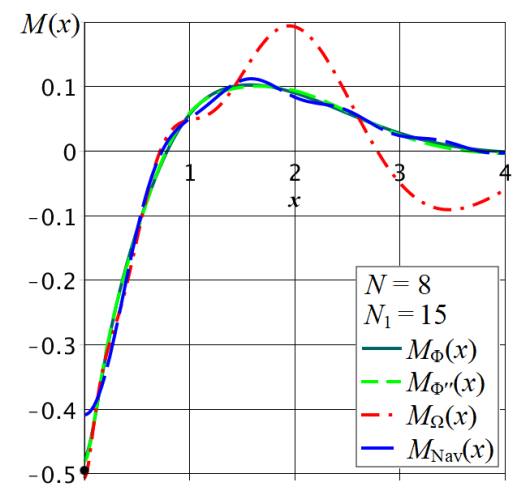

$b$

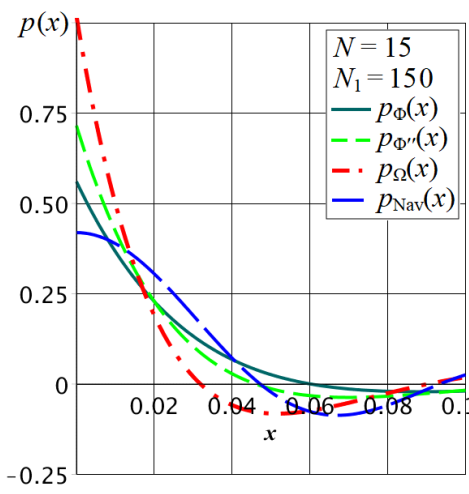

c

Fig. 4. Calculated values of: $(a)$ displacement; $(b)$ moments; $(c)$ outer loading for symmetrical task at length of loading $l=0.01$

in point $x=0$. At whole Galerkin method is the best choice. As to Navier method, it requires much more terms to give the comparable accuracy.

4. Drastically decrease the length of action of outer loading up to $l=0.01$. All calculation results are given on Fig. 4. All mentioned above tendencies are revealed here again. We only note, that much more terms, especially for Navier method are now required. Also note that LSM gives big fluctuations at smaller number of terms $N$, and its results are much worse in general, except for outer distributed loading, which hardly can ever be the goal of calculation. Note that adoption $\psi_{m}=\Phi_{m}^{\prime \prime}$ gives the better values of moment, and bold dot on Fig. 4, $b$ is exact value of moment in point $x=0$. In this case Navier method requires a very big number $N_{1}$ of terms.

5. Let's analyze the action of concentrated force at point $x=0$, which actually can be considered as the boundary condition. But in contrast to general recommendations for WRM application [4], an additional trial function $\phi_{0}$ is not used here. Only basic sets of function $\Phi_{k}$ are employed instead for construction of which the boundary condition $\Phi_{k}^{\prime \prime \prime}(x=0)=0$ is used. Results of calculation are shown on Fig. 5. To get the visual correspondence of results now at least 15 terms are needed. The best results for displacement are got for Galerkin method, i. e. $\psi_{m}=\Phi_{m}$. The best results for moment are achieved at $\psi_{m}=\Phi_{m}^{\prime \prime}$ choice, bold dot on Fig. 5, $b$ is exact value of moment in $x=0$. The choice of test functions in form $\psi_{m}=\Omega_{m}$ (LSM) gives big fluctuation and can not be recommended for cases when outer loading is significantly localized.

6. Let's generalize the above results as to their accuracy for tasks with different lengths of outer force action. Determine the minimal number of terms for each method, which provides the required accuracy of $1 \%$ in comparison with exact analytical solution. They are given in Table 1 . In most cases the goal of calculation is not to look for a function itself, but rather its derivatives. Here such value is a bending moment (second derivative). Thus in Table 1 the required number of terms is given for moments. Evidently the proposed WRM based on application of exponential functions has an advantage as compared with Navier method. This is especially exhibited for case of concentrated load, where Navier method requires 300 terms, while

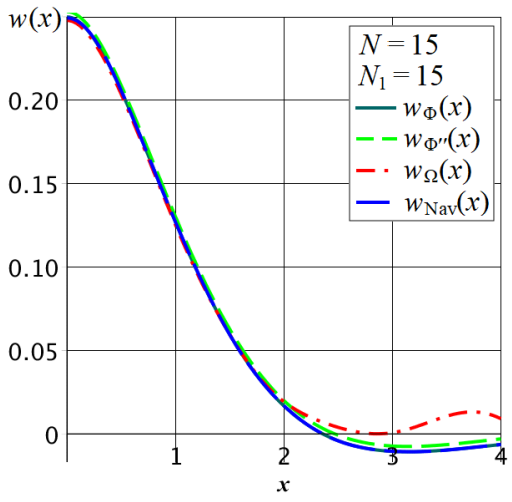

$a$

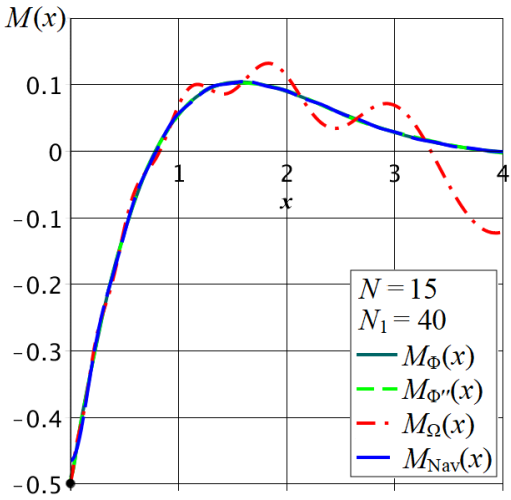

Fig. 5. Calculated values of: $(a)$ displacement; $(b)$ moments for the action of concentrated force at $\mathrm{x}=0$ 
WRM based on test functions $\psi_{m}=\Phi_{m}^{\prime \prime}$ or $\psi_{m}=\Phi_{m}$ allows for $\sim 20$ terms only.

Table 1. Minimal quantity of terms $N_{\min }$ necessary to provides $1 \%$ accuracy for bending moment

\begin{tabular}{|c|c|c|c|c|}
\hline \multirow{2}{*}{$\begin{array}{c}\text { Length of } \\
\text { loading }\end{array}$} & $\begin{array}{c}\text { Exact value } \\
\text { for moment } \\
\text { at } x=0\end{array}$ & $\begin{array}{c}\text { Navier } \\
\text { method }\end{array}$ & \multicolumn{2}{|c|}{$\begin{array}{c}\text { Proposed method, } \\
\text { test functions in } \\
\text { WRM }\end{array}$} \\
\cline { 4 - 5 } & & & $\Phi_{m}$ & $\Phi_{m}^{\prime \prime}$ \\
\hline$l=0.5$ & 0.29079 & 22 & 8 & 8 \\
\hline$l=0.1$ & 0.45167 & 42 & 8 & 7 \\
\hline$l=0.01$ & 0.49502 & 154 & 16 & 13 \\
\hline$l \rightarrow 0$ & 0.5 & 284 & 23 & 18 \\
\hline
\end{tabular}

Other boundary conditions. In 2D applications socalled "beam functions" are very often used which are solutions of much simple 1D problems for beam. So 1D elaborated procedures are needed for future more complicated geometries. Proposed variant of WRM has not only single advantage over Navier method as to analysis of concentrated force. Other evident advantage - its simple adaptation to different boundary conditions. Note that in Navier method only special combinations of them can be analyzed. To demonstrate it, consider the action of concentrated force on free edge of shell (beam) so the following boundary conditions are considered:

$$
Q(0)=1 \cdot \delta(x=0), \quad M(0)=0,
$$

where $\delta(x)$ is Dirac delta function. Similarly to above, construct the set of functions $\Phi_{k}(x)$ :

$$
\begin{gathered}
\Phi_{k}(x)=\lambda_{k, 0} \Gamma_{k}+\lambda_{k, 1} \Gamma_{k+1}+\lambda_{k, 2} \Gamma_{k+2}, \quad 0 \leq x \leq \infty, \\
\Phi_{k}^{-}(-x)=\Phi_{k}(x), \quad-\infty \leq x \leq 0,
\end{gathered}
$$

which satisfy free boundary conditions:

$$
\Phi_{k}^{\prime \prime}(0)=\Phi_{k}^{\prime \prime \prime}(x)=0 \text {. }
$$

Take $\lambda_{k, 0}=1$, then two other coefficient are related with it:

$$
\lambda_{k, 0}=1, \quad \lambda_{k, 1}=-\frac{2 k^{2}}{(k+1)^{2}}, \quad \lambda_{k, 2}=\frac{k^{2}}{(k+2)^{2}} .
$$

The strict solution of this task is given by formula:

$$
w(x)=\exp (-x)\left(\frac{1}{2} \cos x\right) .
$$

Check the accuracy of our variant of WRM. Note again that application of Navier method is impossible here. Another peculiarity of application of WRM is that
$\Phi_{m}^{\prime \prime}(x=0)=0$, and this excludes the possibility of adoption of $\Phi_{m}^{\prime \prime}$ as the test function, because free column in (8d) becomes equal to zero. As result only two test functions $\psi_{m}=\Phi_{m}$ and $\psi_{m}=\Omega_{m}$ are considered. On Fig. 6 the corresponding graphs of displacements and moments are shown for number of terms $N=15$, for the sake of comparison the exact solution is given too. Galerkin method provides good accuracy for displacements and moments even with the number of terms $N=5$. Application of $\psi_{m}=\Phi_{m}$ at $N=15$ provides almost perfect accuracy. As to adoption $\psi_{m}=\Omega_{m}$, it gives much worse accuracy, as was noted in above tasks.

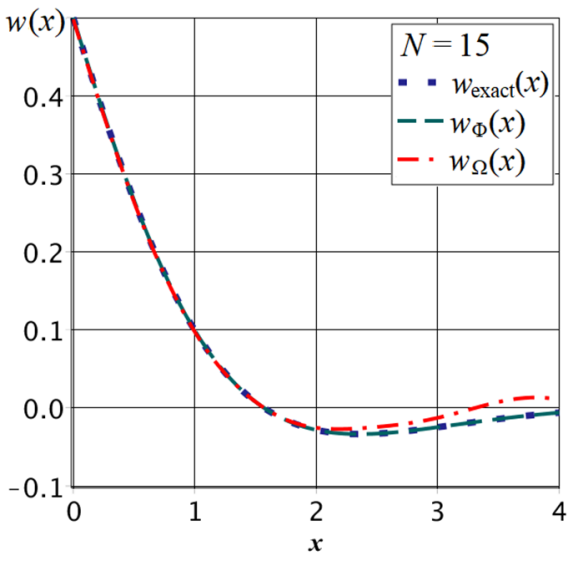

$a$

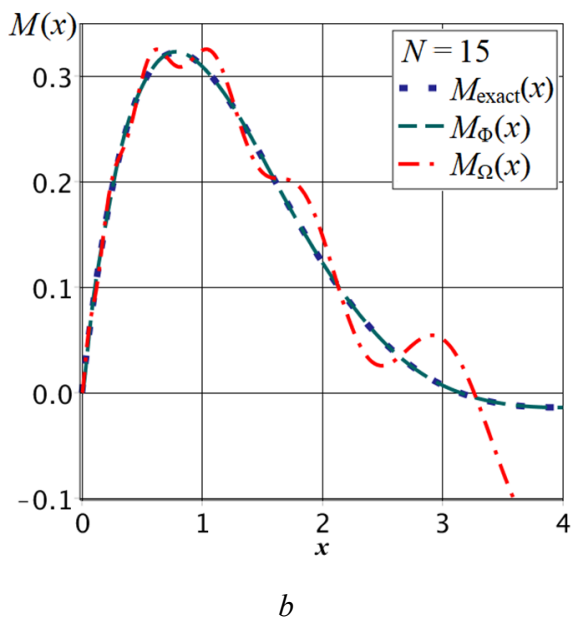

Fig. 6. Calculated values of: (a) displacement; $(b)$ moments at action of concentrated force at free edge

\section{Conclusions}

This work is methodological one, and on example of wide known $4^{\text {th }}$ order differential task for axisymmetrical shell it demonstrates the peculiarities and advantages of application of exponential functions in WRM. Special attention is given to choice of test functions, their justification and to consideration of action of concentrated force on the 
boundary, while the trial functions satisfy to some zeros boundary conditions.

1. It is suggested to use special symmetrical or asymmetrical sets (combinations) of consequent exponential functions, which satisfy different combinations of zero boundary conditions. The technique of their determination is described. As in Navier method the possibility of omitting the number zero function $\phi_{0}$, which usually chosen to satisfy non zero boundary condition, is demonstrated. This simplifies the procedure of application of WRM.

2. Proposed method has noticeable advantage over Navier method in case of action of concentrated or localized forces. To achieve the similar accuracy it requires lesser terms, at least, in tens times as compared with Navier method.

3. Influence of choice of test functions on the accuracy of method is carefully investigated. It was shown that application in this capacity of odd derivative of trial function (even with artificially changed symmetry) gives very strange results. Attention is needed when outer force is concentrated one, then trial function should have non zero values in point of force application. Generally speaking, the best choice of test function is the trial function itself (Galerkin method). Yet sometimes choice of test function as a second derivative of trial one can provide the best results for a bending moment. LSM sometimes requires too much terms, and is inferior one as compared with two above methods.

\section{References}

[1] K.-J. Bathe, Finite Element Procedures. 2nd ed. Klaus-Jurgen Bathe, Watertown, MA, 2016,1065 p. https://doi.org/10.1201/9781315641645-2

[2] N.G. Afendikova, "Istoriya metoda Galerkina i ego rol' v tvorchestve M.V. Keldysha", Preprinty IPM im. M.V. Keldysha, no. 77, pp. 3-17, 2014, https://doi.org/10.1007/s15015-014-1378-5

[3] S.P. Demidov, Teoriya uprugosti [Theory of elasticity]. Moscow, Russia: Vyssha shkola, 1979, 432 p.

[4] C.A.J. Fletcher, Computational Galerkin methods. Springer-Verlag, New-York, 1984, 320 p. https://doi.org/10.1007/978-3-642-85949-6

[5] S.P. Timoshenko and S. Woinowsky-Krieger, Theory of plates and shells. 2nd ed. McGraw-Hill Inc New York, 1959,595 p.

[6] I. Elishakoff, A.P. Ankitha and A. Marzani, "Rigorous versus naïve implementation of the Galerkin method for stepped beams", Acta Mechanica, vol. 230, pp. 3861-3873, 2019. https://doi.org/10.1007/s00707-019-02393-z

[7] G.B. Warburton, "The vibration of rectangular plates", Proc. Inst. Mech. Engrs., vol. 168(1), pp. 371-384, 1954. https://doi:10.1243/PIME_PROC_1954_168_040_02

[8] P. Moreno-García, J.V. Araújo dos Santos and H. Lopes, "A review and study on Ritz method admissible functions with emphasis on buckling and free vibration of isotropic and anisotropic beams and plates", Archives of Computational Methods in Engineering, vol. 25, pp. 785-815, 2018. https://doi.org/10.1007/s11831-017-9214-7

[9] U. Lee, Spectral element method in structural dynamics. John Wiley and Sons (Asia), Singapore, 2009,454 p. DOI: $10.1002 / 9780470823767$

[10] J.T.-S. Wang and C.-C. Lin, "Dynamic analysis of generally supported beams using Fourier series", Journal of Sound and Vibration, vol. 196, no. 3, pp. 285-293, 1996. https://doi.org/10.1006/jsvi.1996.0484

[11] S. Zhang, L.Xu and R. Li, "New exact series solutions for transverse vibration of rotationally-restrained orthotropic plates", Applied Mathematical Modeling, vol. 65, pp. 348-360, 2019. https://doi.org/10.1016/j.apm.2018.08.033

\section{Застосування експоненціальних функцій в методі зважених нев'язок в структурній механіці на прикладі осесиметричної задачі оболонки}

\section{І. В. Ориняк, Ю. П. Бай}

Анотація. Метод зважених нев'язок набув широкої популярності протягом останніх років, особливо завдяки застосуванню в методах скінчених елементів. Він полягає в наближеному виконанні диференціальних рівнянь, тоді як граничні умови мають виконуватись точно. Ця мета досягається правильним вибором множин пробних (базових) функиій, які дають нев'язки. Нев'язки множать на вагові функиіі та мінімізують, інтегруючи по всій області задачі. Множина пробних і вагових функцій визначає особливість та переваги кожного конкретного методу. Найбільш популярним є вибір пробних $і$ вагових функиій у вигляді тригонометричних або поліноміальних функиій. У двовимірних задачах часто використовуються так звані “балочні функиї”, які є рішеннями більш простих одновимірних задач для балки.

В даній методичній роботі ми досліджуємо можливість використання множин функиій, побудованих на послідовних експоненціальних функціях, які точно задовольняють граничним умовам. Метод досліджено на прикладі простої осесиметричної задачі оболонки, точне рішення якої відоме для будь-якого навантаження. Для кількох прикладів розподіленого або концентрованого навантаження запропонований метод порівнюється з аналогічним методом Нав'є, в якому використовуються тригонометричні функиіі. Також ретельно досліджується правильний вибір вагових функиій. Зазначається, ичо запропоновані множини симетричних чи антисиметричних експоненціальних функцій мають хорошу перспективу для застосування в більи складних задачах структурної механіки.

Ключові слова: осесиметрична оболонка, розподілене навантаження, концентрована сила, метод Нав'є, метод БубноваГальоркіна, множина експоненціальних функиій. 


\title{
Применение экспоненциальных функций в методе взвешенных невязок в структурной механике на примере осесимметричной задачи оболочки
}

\author{
И. В. Орыняк, Ю. П. Бай
}

Аннотация. Метод взвешенных невязок приобрел широкую популярность в последние годы, особенно благодаря применению в методах конечных элементов. Он состоит в приближенном выполнении дифференциальных уравнений, тогда как граничные условия должны выполняться точно. Эта цуель достигается правильныл выбором множества пробных (базовых) функций, которые дают невязки. Невязки умножают на весовые функции и минимизируют, интегрируя по всей области задачи. Множество пробных и весовых функиий определяет особенность и преимушества каждого конкретного метода. Наиболее популярныл является выбор пробных и весовых функций в виде тригонометрических или полиномиальных функций. В двумерных задачах часто используются так называемые "балочные функиии", которые являются решениями более простых одномерных задач для балки.

В данной методической работе мы исследуем возможность использования множеств функций, построенньх на последовательных экспоненциальных функииях, которые точно удовлетворяют граничным условиям. Метод исследован на примере простой осесимметричной задачи оболочки, точное решение которой известно для любой нагрузки. Для нескольких примеров распределенной или кониентрированной нагрузки предложенный метод сравнивается с аналогичным методом Навье, в котором используются тригонометрические функции. Также тщзательно исследуется правильный выбор весовых функций. Отмечается, что предложенные множества симметричных или антисимметричных экспоненциальных функций имеют хорошую перспективу для применения в более сложных задачах структурной механики.

Ключевые слова: осесимметричная оболочка, распределенная нагрузка, концентрированная сила, метод Навье, метод Бубнова-Галеркина, множество экспоненциальных функций. 